\title{
UN TÍMPANO ROMÁNICO INÉDITO PROCEDENTE DE LABASTIDA (ALAVA)
}

En el claustro del Museo de San Telmo de San Sebastián se conservan, empotrados en una pared, restos de un tímpano que ha pasado desapercibido hasta la fecha. Unicamente conozco una nota explicativa a una foto que aparece en el catálogo del Museo de San Telmo de Gonzalo Manso de Zúñiga, donde señala su procedencia de la localidad alavesa de Labastida, lo fecha en el siglo $x$ y añade que son restos de un sepulcro ${ }^{1}$.

Sin embargo la iconografía nos indica que se trata de un tímpano y que su cronología se sitúa hacia finales del siglo XII o principios del XIII.

De Labastida se conocen hasta once ermitas que han desaparecido -Nuestra Señora de los Angeles de Toloño, Nuestra Señora de Remélluri, San Andrés de Muga, San Clemente, San Cristóbal, Santa Eulalia, El Humilladero, San Julián, San Martín, San Román y Santiago- sin que se sepa en la mayoría de ellas a qué época pertenecieron y de cuál proceden los restos del tímpano ${ }^{2}$.

El tímpano (Fig. 1) presenta a dos ángeles que sostienen un crismón trinitario con las letras habituales, P, S, X, Alfa y Omega. Como es conocido es a partir del tímpano de Jaca cuando se difunde por todo el arte románico este tipo de Crismón que incluye la $\mathrm{S}$ referida al Espíritu Santo.

La parte superior de la $\mathrm{P}$ está parcialmente fracturada, por lo que no sabemos si en esta parte tendría cruz o si carecería de ella, pero en cualquier caso parece difícil que, a parte de la duda de la cruz, pudiese existir otro elemento iconográfico en esa parte del tímpano. Los dos ángeles que sostienen el crismón están también deteriorados, pero se conservan las cabezas nimbadas, se aprecia parte de las vestimentas y las alas, habiéndose perdido en ambos casos la parte inferior, lo que nos impide saber sobre qué superficie se sostendrían o si por el contrario estarían elevados.

El motivo iconográfico de los dos ángeles que sostienen el crismón procede de los soldados que guardaban el Lábaro imperial romano, que se convertirán en victorias aladas que custodiaban dicho estandarte. Este motivo debió servir para desarrollar la conocida fórmula de la imago clipeata en los sarcófagos paganos, esquema que pasará íntegramente a los sarcófagos cristianos que ya hacia el año 400 incorpora el monograma de Cristo ${ }^{3}$. La presencia de los dos ángeles sosteniendo o elevando el crismón trinitario cobra un especial significado eucarístico al encontrarse una invocación a las tres personas en algunos pasajes del Ordo Missae, como ha recordado Serafín Moralejo a propósito del baldaquino de Compostela ${ }^{4}$. En cualquier caso no es una novedad este sentido eucarístico, pues ya desde el siglo II aparece el Cordero junto al crismón, lo que refuerza la idea de salvación de la segunda persona e incide por tanto en el sacramento eucarístico. No olvidemos que la fórmula iconográfica del crismón junto al agnus Dei, fórmula eucarística por excelencia, tuvo una amplia repercusión en el entorno de Alava, y así aparece en Armentia o Aguilar de Codés.

$\mathrm{Al}$ ámbito aragonés se incorporó el motivo de los dos ángeles a partir de las fórmulas creadas por el taller del maestro Gilduin en Saint-Sernin de Toulouse, que ahí lo hacían sosteniendo el busto de Cristo. Luego, los dos ángeles incorporaron el crismón trinitario de origen jaqués hasta completar la fórmula iconográfica que vemos en el tímpano de Labastida y que tanto desarrollo tuvo en el área navarro-aragonés. Así aparecen ángeles sosteniendo el crismón en la por-

\footnotetext{
1 Manso de Zúñiga, Gonzalo: Museo San Telmo, Bilbao, 1976, p. 74.

2 Enciso Viana, Emilio y Cantera Orive, Julián: Catálogo monumental de la diócesis de Vitoria, vol. 1, Vitoria, 1967, pp. 199-206, señalan la existencia documental de estas once ermitas desaparecidas, en algún caso con descripciones o citas hechas hace un siglo.

3 Para este tipo de iconografía vid. Ocon Alonso, D.: Tímpanos románticos en españoles: reinos de Navarra y Aragón, Madrid, Universidad Complutense, 1985, vol. 2, pp. 100-108.

4 Moralejo, Serafín: "Ars sacra et sculpture romane: le trésor et le chantier de Compostelle», en Ler cahiers de SaintMichel de Cuixà, 11 (1980), p. 215.
} 


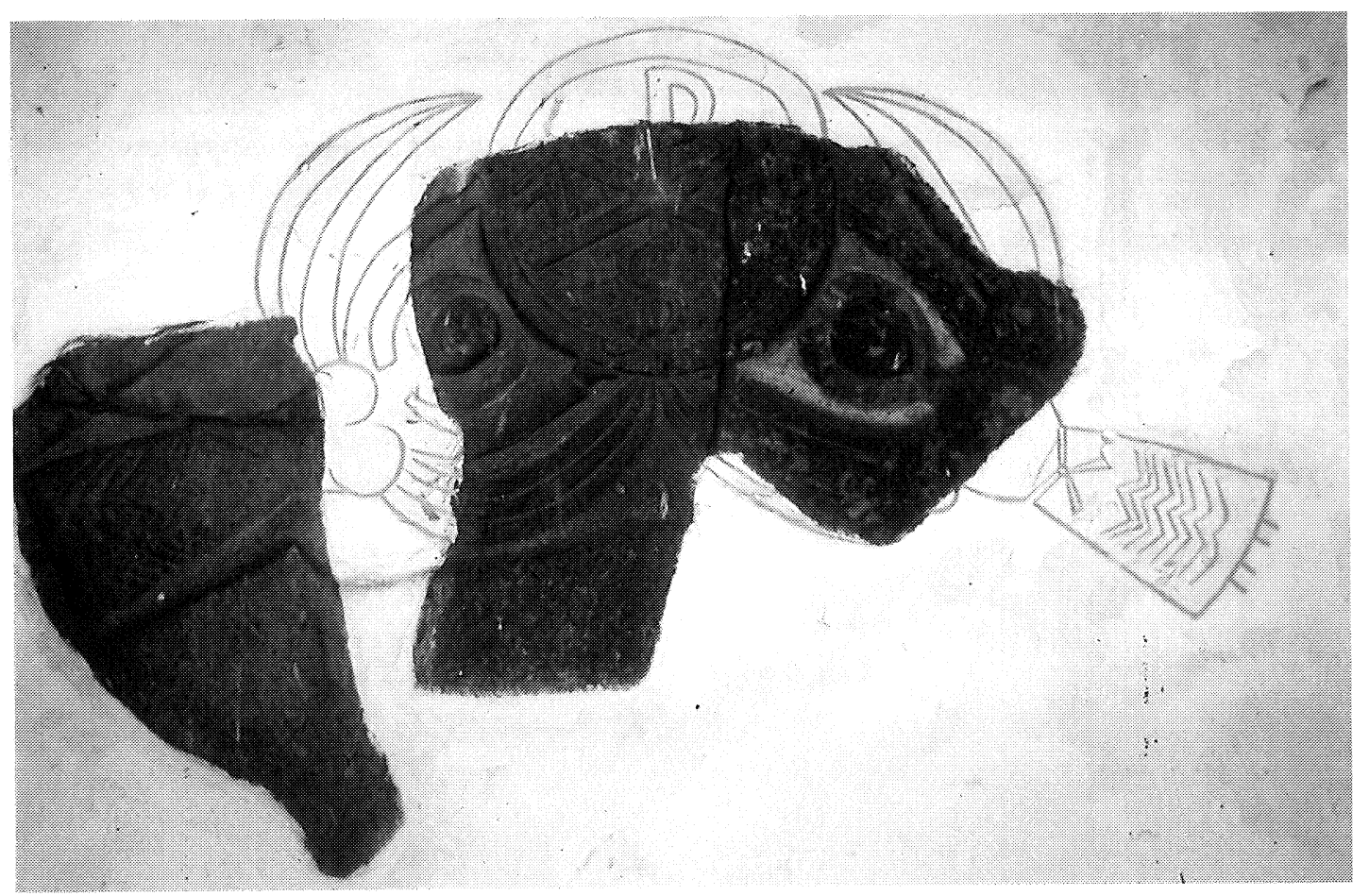

Fig. 7. Restos del tímpano procedentes de Labastida (Álava). San Sebastían, Museo de San Telmo.

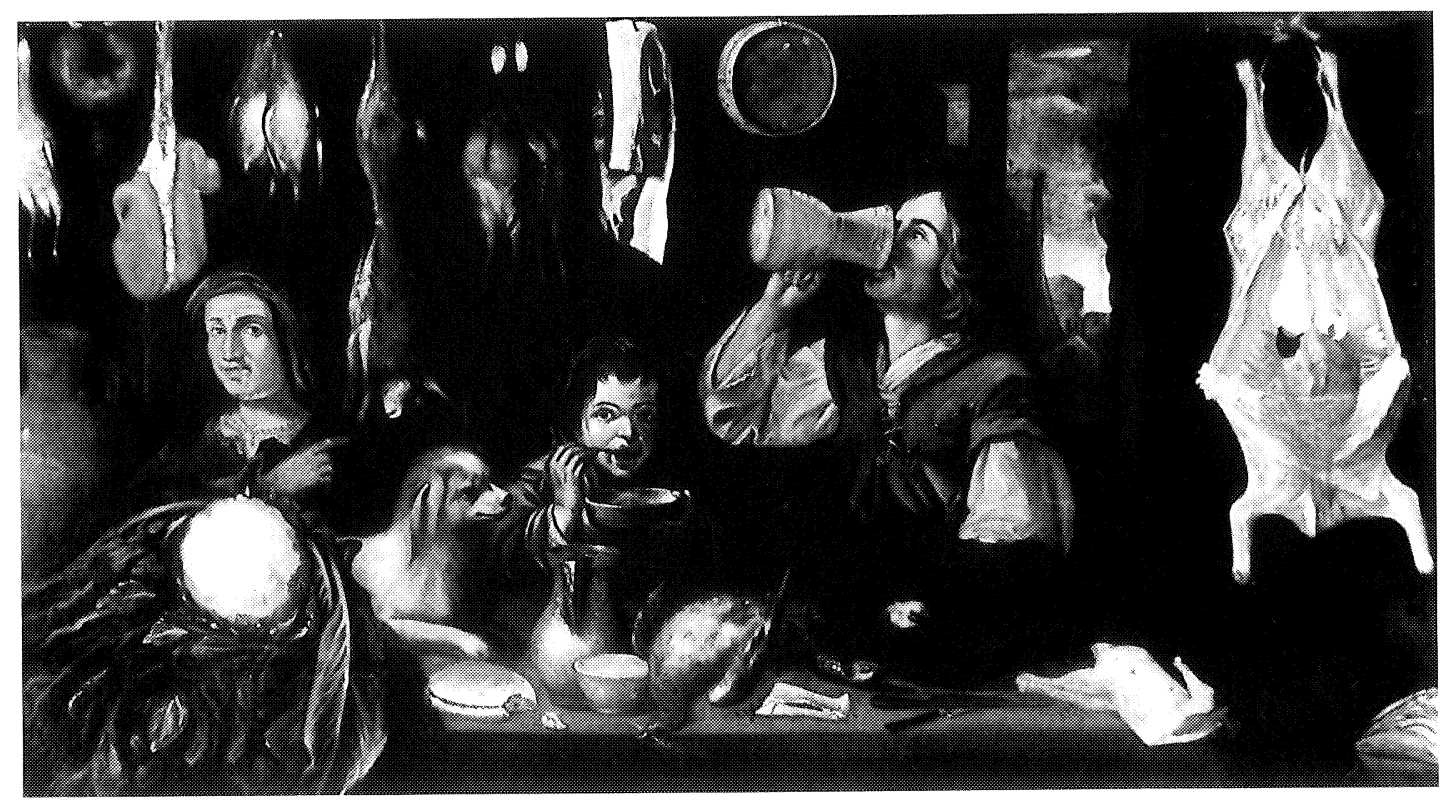

Fig. 8. Carrillo, Bodegón. Madrid, Comercio de Arte. 
tada oeste de San Salvador de Ejea de los Caballeros (Zaragoza), San Pedro el Viejo de Huesca, San Felices de Uncastillo (Zaragoza), Tamarite de Litera (Huesca), Sainte Engrace (Pyrénées). De todas éstas la primera receptora de la iconografía del crismón sostenido por dos ángeles se encuentra en San Pedro el Viejo de Huesca hacia la mitad del siglo xIr; luego estaría la iglesia de Sainte Engrance y Tamarite que se fechan hacia el último tercio del siglo xII; Uncastillo todavía se sitúa en el siglo xII, hacia su final, y Ejea de los Caballeros sobrepasa las primeras décadas del xiII. Para Labastida no contamos con fechas precisas, pero teniendo en cuenta las anteriores y su factura popular, todo nos induce a creer que estaría más cerca de la última que de la primera.

Estilísticamente el tímpano de Labastida presenta unas características sumamente populares. Se trata, en efecto, de un escultor rural que interpreta una iconografía oficial, y como suele ser frecuente en este tipo de obras populares, no se encuentran relaciones estilísticas claras. De hecho, con los otros cuatro tímpanos existentes en Alava -Añes, Zambrana y dos en Armenia- no guarda ninguna relación estilística, aspecto que es extensivo a los dos únicos crismones alaveses existentes, el de Armentia y el de Zambrana.

Agustín Gómez Gómez

Doctor por la Universidad del País Vasco

\section{UN BODEGÓN FIRMADO POR «CARRILLO»}

El número de cuadros firmados, dentro de la pintura española es tan relativamente escaso que siempre es de celebrar la aparición de uno de ellos con estas características. Es el caso del bodegón que nos ocupa $(1,25 \times 2,25 \mathrm{~m})$, en el comercio, y del cual sabemos el nombre del autor, Carrillo, cuya firma se encuentra en el papel del envoltorio situado en el centro de la composición (Fig. 8 y 9.)

Desafortunadamente, nada mas se sabe de este artista. Tan sólo el «Lexikon» ${ }^{1}$ menciona a un tal Juan Carrillo, ubicándolo en Sevilla hacia 1513. Esta fecha no coincide con la del cuadro estudiado ya que la aparición del bodegón en España se sitúa a finales del xVI y, dados los elementos presentes en esta obra, no se puede aceptar una datación anterior.

La obra es interesante al tratarse de un "Bodegón» en el más estricto sentido de la palabra ${ }^{2}$, en el cual las figuras humanas aparecen en un interior mezcladas con alimentos. Esta definición de bodegón procede del "Tesoro de la Lengua española» de Covarrubias (1611) donde aparece el término como: «El sótano o portal baxo, dentro del cual está la bodega a donde el que no tiene quien le guise la comida la halla allí aderezada y juntamente con las bebidas». Dos años antes, en 1599, se recogen, en el testamento de Pantoja de la Cruz y como pintados por él, unos "bodegones de Italia, pinturas grandes». No se sabe con precisión el tipo de pintura a la que alude pero trae a la memoria las obras del norte de Italia las cuales, fechadas en época similar e imbuídas de un aire flamenco, serían llamadas «bodegones» en España. Estos cuadros recogen escenas con vendedores de aves, de pescados o de frutas ${ }^{3}$. El cuadro que nos ocupa encaja a la perfección dentro

\footnotetext{
1 "Allgemeines Lexikon der Bildenden Künstler», Thieme-Becker, 1932, T. VI: "Carrillo, Juan: spanische Maler in Sevilla um 1513".

2 Véase Pérez SÁnchez: "La Nature Morte espagnole de XVIIe ème siècle a Goya», 1971, pp. 13-16.

3 Ver: Pérez SÁnchez: «Pintura española de bodegones y floreros. De 1600 a Goya», Catálogo Exposición Museo del Prado, 1983, p. 24. Por su parte, en el Diccionario de la Real Academia Española se define «bodegón» como «Tienda donde se guisa y se sirven comidas ordinarias». De estas dos últimas acepciones, que identifican el bodegón con la venta de algún producto alimenticio, puede proceder la idea, sin confirmar, de que estos cuadros colgaban de las paredes a la entrada de tiendas o mesones, anunciando la mercancía.
} 